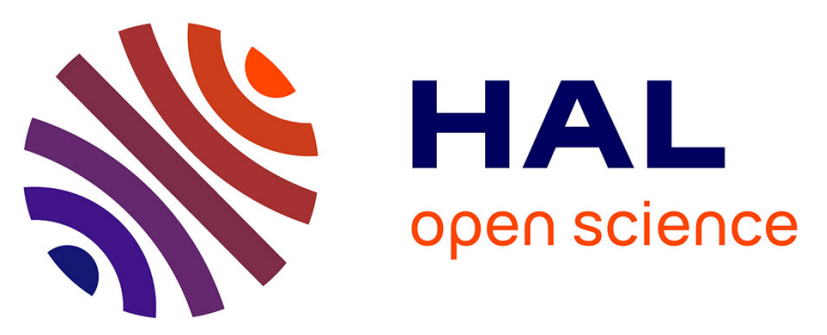

\title{
Instrumentation of Higher Education Modules Based on Synchronous Speech Transcription: Design and Integration of a Toolset During Lectures and Practical Work Sessions
}

\author{
Vincent Bettenfeld, Rémi Venant, Claudine Piau-Toffolon, Christophe \\ Choquet
}

\section{To cite this version:}

Vincent Bettenfeld, Rémi Venant, Claudine Piau-Toffolon, Christophe Choquet. Instrumentation of Higher Education Modules Based on Synchronous Speech Transcription: Design and Integration of a Toolset During Lectures and Practical Work Sessions. IEEE 19th International Conference on Advanced Learning Technologies (ICALT 2019), IEEE, Jul 2019, Maceió, Brazil. pp.22-23, 10.1109/ICALT.2019.00018 . hal-03159277

\section{HAL Id: hal-03159277 \\ https://hal.science/hal-03159277}

Submitted on 4 Mar 2021

HAL is a multi-disciplinary open access archive for the deposit and dissemination of scientific research documents, whether they are published or not. The documents may come from teaching and research institutions in France or abroad, or from public or private research centers.
L'archive ouverte pluridisciplinaire HAL, est destinée au dépôt et à la diffusion de documents scientifiques de niveau recherche, publiés ou non, émanant des établissements d'enseignement et de recherche français ou étrangers, des laboratoires publics ou privés. 


\title{
Instrumentation of Higher Education Modules Based on Synchronous Speech Transcription
}

\author{
Design and integration of a toolset during lectures and practical work sessions \\ Vincent Bettenfeld, Remi Venant, Claudine Piau-Toffolon, Christophe Choquet \\ Laboratoire d'Informatique de l'Université du Mans, Equipe IEIAH \\ Laval, France \\ \{firstname.surname\}@univ-lemans.fr
}

\begin{abstract}
This article presents a web-based toolset, the process leading to its design as well as its experimentation with real users. This device uses synchronous speech transcription to provide students with a textual version of the teacher's speech during class, as well as offering different functionalities. The goal of this instrumentation is to explore the potential of synchronous transcription in classes.
\end{abstract}

Keywords-component; synchronous speech transcription; web-based toolset; Moodle plugin

\section{INTRODUCTION}

The presented works are part of the PASTEL research project (Performing Automated Speech Transcription for Enhancing Learning), exploring the usability of synchronous speech transcription in teaching and learning activities. This article presents the design, the interface, and the user tests of a web-based environment allowing students to attend a class while getting live subtitles of the teacher's speech in traditional, remote or blended classroom situations. The speech transcription also used in asynchronous contexts, and other tools additionally proposed in both situations are presented.

Subtitles for the classroom have been experimented in the past, particularly as a way to support accessibility of students speaking foreign languages and students hard of hearing [4]. Also, when recordings of the class are made available afterwards, it appears that students are focusing more on the actual teacher's speech than on their activity of note-taking, which decreases their anxiety since no information can be lost due to inattention.

Integrating such system in class means providing devices able to process data and communicating between each other in real time. Taking advantage of this data exchange is an opportunity to offer other functionalities based on shortlatency analysis of these exchanges.

\section{NEEDS AND PRACTICES ANALYSIS}

An analysis of needs and pre-existing uses was conducted, using a double approach both quantitative and qualitative. A questionnaire was handed to students and an interview was carried out with an associate professor, as well as other teachers during the continuation of the project. Results of this study are presented in detail in [3]. Among students encountering difficulties, $61 \%$ declare coming across with comprehension problems. $53 \%$ declare that easier possibilities of interactions with the teacher would help them. The teachers were looking forward to being able to know where the students encountered the biggest difficulties, allowing them to update their lessons and providing more explanations at the right time. These practices and needs guided our choices in the implementation of functionalities in the device.

The toolset produced was implemented as a Moodle plugin. Moodle is an open-source learning management system which is already used by the universities taking part in this project.

\section{LECTURE INSTRUMENTATION}

The instrumentation of lecture was described extensively in a previous publication [1]. The main pieces of information are presented in this section.

The different technologies on which our toolset is based are developed by different research teams and hosted on different servers. The teacher's speech is recorded on line and the audio data are directly sent to a transcription server, that eventually returns the resulting transcription to the Moodle server. This transcription is also transmitted to an engine which extracts the most important keywords and selects relevant learning documents. The transcription and links to these documents are stored on the Moodle server and displayed on the web interfaces of students and teachers in real time. This Moodle server also supports the communications between these human actors. Clicks on different interface elements are monitored by saving them as dedicated events in the Moodle database, allowing further behavioral analysis afterwards.

Students' interface shows the video stream of the teacher, as well as his speech's transcription updated on the go. Students can find the slides displayed in the classroom, a text editor to take notes, a list of recommended resources, and a system to send messages to the teacher. On his interface, the teacher can see feedback of the video, the currently displayed slide, as well as indicators of students' activities and their messages. 


\section{GROUP WORK INSTRUMENTATION}

The activity instrumented during the experiment was identified prior to the group-work plugin design, thus it was enriched with functionalities relevant in this specific context. The original activity included the use of external tools, and among them the use of the management tool Trello was mandatory. This tool was used by the teacher to control how students managed their projects. Its web API is available for retrieving data from existing projects; since the intent of our toolset is to centralize a maximum of functionalities used by participants, we tested the compatibility with external tools by integrating a feedback on the Trello projects in our architecture. Another major difference was the use of speech transcription. Students are required to produce a report about their work. The transcription was then changed to equip the students rather than teachers and let them dictate their reports.

Additionally, the recordings of the teacher's lecture are available for consultation and retrieval of information. Another service was introduced in this context: segmentation of the transcription into chapters, as well as separation of the portions of sentences based on pauses taken during the pronunciation of the speech. This service is also in the prototype stage [2]. Since it takes too much time to operate this information synchronously, this service was only given during the group work, after the lecture.

Even before considering the particular student activity described in the next section, the plugin was developed in the intent to ease retrieving information dispensed during lectures. Afterwards, one can watch these lectures through a video player, enhanced and synchronized with the transcription. Clicking on one part of the latter automatically set the player on the corresponding moment of the video. Alternatively, instead of scrolling and looking for an individual sentence, users can browse a list of chapters, and click to access them in the video player. Given the activity of the work groups, the speech transcription device was installed locally on the computer, and by the click of a button the transcription was inserted in a text editor. The last tab displays the Trello indicators, as a feed of the most recent operation, as well as graphs showing the tasks allocated to different students and categories.

The teachers' interface is similar to the student's one. In addition to the tabs described, the teacher can select a Moodle group, displayed with its name and its members. The content of the text editor and the indicators is then updated for the corresponding group, allowing the teacher to monitor its activity.

\section{EXPERIMENTATIONS IN AUTHENTIC CONTEXT}

The device was tested in simulated hybrid configuration during an Information and Communication class given to students in second year of higher education. Students judged the transcription accurate enough to be used as subtitles. They were relatively overwhelmed by the number of functionalities on a single interface, and the teacher declared that a comprehensive use of these functionalities would be efficient if planned throughout a whole module. The two variants of this environment were later tested in January 2019 during a project management class with student enlisted in a master's degree in computer science. The class included 5 students whose native language was not the language in which the class was given. Similarly, to the previous experiment, the screen activity was recorded in video format. During the lecture, students were divided in two groups positioned in two separate classrooms. The remote group attended the lecture entirely through the interface. During group work, students were divided into six groups of 3 to 5 members, distributed through two neighboring classrooms. Students were asked to complete a technical production, as well as a report on their activity. Their advancements had to be reflected on the project management tool. Trello

Traces and videos have been archived and will be investigated shortly. The main interests include the analysis of the behavior of students browsing the transcription during group works, as well as the difference in behavior between native speaker students and non-native speakers. Other interviews were conducted with teachers participating in future studies in order to favor co-design of software components fulfilling ad hoc needs. One of these components allows students to fill multiple choices questionnaires in real time. These interviews allow us to gather parameters expressed by teachers to limit, to a certain extent, functionalities in synchronous situations: most notably to deactivate the synchronous recommendation of resources addressed to younger students to prevent them from being distracted in class. These resources still ought to be generated depending on slides content and speech, and available for export and the end of the class. This functionality was desired by $70 \%$ of students during the initial needs analysis study.

\section{ACKNOWLEDGMENT}

The current work is supported by the ANR project PASTEL $<$ ANR-16-CE38-0007>. The authors would like to thank the others participants of the project for their collaboration.

\section{REFERENCES}

[1] V. Bettenfeld, C. Choquet, C. Piau-Toffolon. Lecture instrumentation based on synchronous speech transcription. 18th International Conference on Advanced Learning Technologies, pp. 11-15, Jul 2018.

[2] D. Charlet and G. Damnati, "Linking written News and TV Broadcast News topic segments with semantic textual similarity" in Proceedings of the Eleventh International Conference on Language Resources and Evaluation (LREC 2018), may 2018.

[3] F. Pirolli, R. Cretin-Pirolli. Apports de la transcription automatique de la parole pour l'instrumentation de séquences pédagogiques et l'enrichissement des environnements personnels d'apprentissage. Échanger Pour Apprendre en Ligne, Jun 2018.

[4] A. Steinfeld. The benefit to the deaf of real-time captions in a mainstream classroom environment. Diss. University of Michigan, 1999. 